\title{
ORGANIZATIONAL CULTURE AND INTENTIONS TOWARDS TYPES OF WHISTLEBLOWING: THE CASE OF TURKEY AND ETHIOPIA
}

\author{
DOI: 10.17261/Pressacademia.2017.759 \\ RJBM-V.4-ISS.4-2017(8)-p.527-539 \\ Fathe Mahdi Wozir ${ }^{1}$, E. Serra Yurtkoru ${ }^{2}$ \\ ${ }^{1}$ Marmara University, Istanbul, Turkey. fathemahdi.wozir@marun.edu.tr \\ ${ }^{2}$ Marmara University, Istanbul, Turkey. syurtkoru@marmara.edu.tr
}

\section{To cite this document}

Wozir, F. M. and Yurtkoru, E. S. (2017). Organizational culture and intentions towards types of whistleblowing: the case of Turkey and Ethiopia. Research Journal of Business and Management (RJBM), V.4, Iss.4 , p.527-539.

Permanent link to this document: http://doi.org/10.17261/Pressacademia.2017.759

Copyright: Published by Press Academia and limited licenced re-use rights only.

\begin{abstract}
Purpose- Whistleblowing, is one of the rarely studied topics in non-western cultures, and none in Ethiopia. Hence, this study explores whistleblowing and the contribution of organizational culture $(O C)$ types on different modes of whistleblowing intentions in Ethiopia along with cross-cultural comparison of the theoretical model in Turkey.

Methodology- Totally 528 employees (Ethiopia, N=274 and Turkey, N=254) were selected as participants. Four organizational culture types and six dimensions of whistleblowing are measured using a multidimensional questionnaire with five-point interval scale.

Findings- Analyses revealed that hierarchical culture significantly and positively contributed to external, anonymous, and formal whistleblowing. Alternatively, clan culture had significant positive contribution to internal and informal whistleblowing, and negative contribution to external whistleblowing. However, there were significant variations in terms of nationality.

Conclusion- The dominant values and beliefs embedded within the culture of an organization tend to predict the most likely preferred and accepted methods of whistleblowing in that particular organization.
\end{abstract}

Keywords: Organizational culture, whistleblowing, Turkey, Ethiopia.

JEL Codes: M14, M10, L10

\section{INTRODUCTION}

Illegal, immoral or illegitimate practices such as corruption, fraud, sexual harassment and the like have been a source of major social and economic crises to the employees, organizations and the society at large. Effective whistleblowing systems play a great role in minimizing or stopping such unethical practices. About one-third of organizational wrongdoings are exposed by a report obtained from whistleblowers. Compared to internal or external audits, the tips gained from whistleblowers was found to be more productive (Nayır, Rehg, \& Asa, 2016).

When employees decide to report organizational wrongdoing, they might face dilemmas concerning to whom to raise their concern. This is because, the selection of the recipient is very important as it may affect the reaction of the organization to the informer, the value of the whistleblowing and type of retaliation (Dworkin \& Baucus, 1998). MacNab et al. (2007) classified whistleblowing in to four major types: internal reporting, internal whistleblowing, external reporting and external whistleblowing. They have studied the impact of culture on whistleblowing and they have found that culture has a very influential role on whistleblowing activity, reluctance to whistleblowing and tendencies towards whistleblowing. In addition, Park, Blenkinsopp, Oktem, and Omurgonulsen (2008) categorized whistleblowing in to six types; external, internal, anonymous, identified, formal and informal. They posited that each of these whistleblowing types have significant and distinctive characteristics. They also argued that each type of whistleblowing is associated with the existing cultural values, context and personal character in different ways.

As stated, organizational culture plays an important role in enhancing the effectiveness of whistleblowing systems. Policies related to whistleblowing need to be altered based on organizational culture. They should be customized to the specific organizational cultural values since polices formulated in other settings might not work well for all situations (Loyens, 2013). It is possible for management to forecast the possibility of whistleblowing occurrence and more preferred mode of 
reporting by understanding dimensions of national and organizational culture. Tavakoli, Keenan, and Karanovic (2003) are also of the view that if management is well aware of the relationship between cultural values and preferred mode of reporting, it will assist them as input when they establish protocols for reporting, developing structures and communication systems. Understanding the relationship also helps as an input for what management needs to be aware of when formulating lines of communication, reporting protocols and management structures.

The majority of whistleblowing research was conducted in a western countries giving a lesser consideration to many other parts of the world. This raises a concern on the acceptance or generalizability of these "western" based findings in other parts of the world. The various socio-economic conditions that exist in different countries have differing impact on how individuals in each country perceive what is ethical or not (Nayır et al., 2016). Therefore, in this study, the relationship between organizational culture and employees' intentions towards types of whistleblowing in Ethiopia and Turkey will be investigated and compared. The study attempts to identify how differences in organizational culture could help to understand differences in preference for various types of whistleblowing.

The remainder of this paper is organized as follows. First, a review of relevant literature is presented, then in the methodology section, sample and the survey instrument are explained. Later, findings of the statistical analyses are given in the results part. The final section of the article is devoted for conclusions drawn and implications.

\section{LITERATURE REVIEW}

\subsection{Whistleblowing}

Whistleblowing is among one of the most important issue in the field of management science that has received greater attention in most developed countries. The media, legislative bodies, academicians and the general public started to increase their attention towards whistleblowing (Vandekerckhove, 2006). Whistleblowing has been defined in several ways. The whistleblowing literature is full of debate as to what constitutes whistleblowing (Philmore, Mohammad, \& Richard, 2013). Generally, whistleblowing denotes an ethical action taken by a person to inform an abuse or wrongdoing in an organization with the aim of stopping the serious danger caused by the abuse (Pierre, 2012). How a society perceives whistleblowing and the role that it plays in that society affects how whistleblowing is defined. In some instances, it used as an instrument to fight corruption and to resolve internal conflicts while in some other instances it is used more as an act of free speech. The various definitions offered differ basically on the context, aim and scope of how whistleblowing is used (Martin, 2010). Whistleblowing definitions started to emphasize the role of whistleblowing in work settings. Whistleblowing is perceived as an act that an employee takes to reveal organizational malpractices that the employer or organizational member is involved with. One of the most popular and widely cited definition is suggested by Near and Miceli (1985) as: "the disclosure by organization members (current or former) of illegal, immoral or illegitimate practices under the control of their employers, to persons or organizations that may be able to effect action" (p. 4). Scientific research has heavily relied on this definition and it is the most commonly used one (Miceli et al., 2008).

There may be substantial distinction in the actual methods by which a whistleblower prefers to reveal organizational wrongdoings. Earlier studies pertaining to whistleblowing have made distinctions between internal versus external methods, and identified versus anonymous (Park et al., 2008). Organizational members who desire to echo a misconduct can do so through a large number of paths. The most straightforward choice that whistleblowers could make is to limit their leak within their company (internal reporting) or to report it to persons or bodies outside their company (external reporting) (Donkin, Smith \& Brown, 2008). Park et al. (2008) offered a typology on how individuals blow the whistle based on three dimensions. Every single dimension denotes a person's choice on how to blow the whistle. The choices include; internally or externally, identified or anonymously and formally or informally. The current study is based on Park et al. (2008) classification of whistleblowing types and uses these six types of whistleblowing as dependent variables to identify their relationships with organizational culture types.

Reporting organizational misconduct and other similar unethical actions to the right people in the organization's hierarchy (who are believed to be able to stop the wrongdoing) is described as internal whistleblowing. The individual(s) who receive the report are within the organization and may include, but not limited to, administrators, supervisors, ethics officers, board of directors and the hotline (Chung, Monroe, \& Thorne, 2004; Finn, 1995). Additional range of internal whistleblowing recipients found in most organizations also include; internal ombudsmen, equity and merit units, counselling departments, fraud investigation units and human resource departments (Donkin, et al., 2008). Related to preference, the majority of research findings showed that internal whistleblowing is preferred by most whistleblowers (Miceli \& Near, 1992). Likewise, due to several costs associated with external whistleblowing, most organizations tend to prefer internal whistleblowing than external reporting (Ponemon, 1994). Internal whistleblowing tends to give a chance for the organization to solve the problem behind closed doors and in internal way. In some cases, internal whistleblowing may be perceived as the employee exhibiting loyalty and commitment to the organization (Somers \& Casal, 1994; Barnett, 
1992), and also as a pro-social act (Miceli \& Near, 1992). Nevertheless, blowing the whistle internally rarely gets acceptance within the organization as it is believed to be threatening and dissent. Thus, in many instances, employees who blow the whistle are possibly silenced or their information may be covered up or disregarded (Miceli \& Near, 1992; Mesmer-Magnus \& Viswesvaran, 2005).

On the other hand, external whistleblowing refers to the reporting of organizational misconduct to a complaint recipient outside of the organization. Those who receive the report may consist several parties in the general public domain such as private and state owned media, professional organizations, regulatory agencies and interest groups (Chung et al., 2004; Miceli \& Near, 1994; Miceli \& Near, 1995). Further recipients of whistleblowing report external to the organization include; watchdogs representing government, trade unions, parliament members, anti-corruption hotlines and journalists (Donkin, et al., 2008). When employees report organizational misconduct to external bodies, it tends to create a severe destruction to the company (Park \& Blenkinsopp, 2009). However, external whistleblowing is more effective in that it brings a change within the company. This is possibly due to the attention it brings from outside stakeholders which creates more pressure on the company to respond to the misconduct reported (Dworkin \& Baucus, 1998). Previous studies revealed that, compared to internal whistleblowers, external whistleblowers are more likely to face greater reprisal from colleagues in the organization (e.g., Near \& Miceli, 1986; Dworkin \& Baucus, 1998). Employees who blew the whistle anonymously and were unsuccessful to hide their identity have also encountered greater reprisal (Miceli \& Near, 1994).

When employees reveal organizational misconduct using their real name (providing information that recognizes the individual employee personally), it is referred as Identified whistleblowing. Contrary to this, when employees report organizational misconduct by hiding information about themselves and or by using assumed or artificial name is referred as anonymous whistleblowing (Park et al., 2008). When employees use anonymous way, it tends to enhance the reporting of organizational misconducts such as fraud and corruption since the perceived personal cost of blowing the whistle becomes lesser (e.g., Kaplan \& Schultz, 2007; Robinson, Robertson, \& Curtis, 2012). Anonymous reporting enables whistleblowing systems more effective to discern fraud. A study conducted using large- scale multivariate analysis in Australia revealed the existence of a positive relationship between anonymous reporting channel and reported fraud (Johansson \& Carey, 2015). However, it has been argued that probing anonymous report is hard and is rarely protected under law (Park, Blenkinsopp, \& Park, 2014). Blowing the whistle anonymously tends to make the disclosure easier for the whistleblower but it creates difficulties on the investigation of the problem (Vandekerckhove, 2010). Based on the communication methods, styles or systems used already in the organization to reveal organizational misconduct, it is possible to classify whistleblowing as either formal or informal. When employees report organizational misconduct by following standardized lines of communication or official protocols of the organization, it is referred as formal whistleblowing. On the other hand, informal whistleblowing refers to a situation in which the employee who observed organizational misconduct personally reveals it to his/her close companions or to somebody he/she trusts about the wrongdoing. In addition, it is also possible to differentiate between unauthorized and authorized whistleblowing and formal whistleblowing could be taken as authorized (Park et al., 2008).

\subsection{Organizational Culture}

There are several definitions given to organizational culture. Defining organizational culture universally has been obscure (Lewis, 2002). Almost about 150 different definitions have been identified for culture (Cameron \& Quinn, 2006). Organizational culture has been commonly defined as shared values, beliefs and assumptions present among staffs within an organization. It tends to assist in regulating and managing behavior in the workplace (Schein, 1991). Values and beliefs begin to develop from the constant negotiation and practices among employees in an organization. The emerged values and beliefs develop through time and turn out to be a foundation for what is thought appropriate or inappropriate in a company with regards to right and wrong behavior (Maclntosh \& Doherty, 2010). Some popular definitions of organizational culture include; the collective programming of the mind which differentiates employees in one organization from other employees in another organization (Hofstede, 1990), values and norms that describe a corporation and that impact features of an organization's operation (Trice \& Beyer, 1993), shared meaning among organizational members working in a given company and patterns of belief, rituals and norms used as a social glue (Smircich, 1983), and attitudes, beliefs, and values shared by organizational members and customs belonging to a given social unit (Martin \& Siehl, 1983). Social glue is commonly considered as a metaphor to culture/organizational culture. The cultural elements that unifies them include; the shared beliefs, values, norms, and understandings. Organizational culture plays a role in preventing fragmentation, clashes, pressure, and other despairs. It makes the organizational life to possess harmony, consensus and communality (Alvesson, 2002).

Cameron and Quinn (2006) explained the concept of organizational culture relatively in a more explicit and simple way. According to the authors, organizational culture comprises "the taken-for-granted values, underlying assumptions, expectations, collective memories, and definitions present in an organization and they shortly described it as- how things are around here" (p. 16). They further stated that organizational culture reflects the dominant ideology that exists inside 
individuals' mind, conveys a sense of identity to workers and gives the unwritten and unspoken rules that instruct on how to get along in their workplace. The current study bases its analysis on this definition and tries to look at the typology of organizations based on the computing values framework (CVF). The CVF identifies two major dimensions placing the indicators in to four clusters. One of the dimension separates effectiveness criterion that focuses on flexibility, discretion and dynamism vs. stability, order and control. The other dimension distinguished effectiveness criterion from the one focusing on external orientation, differentiation and rivalry vs. integration, internal orientation and unity. Figure 1 below shows the two dimensions forming the four clusters: hierarchy, clan, market, and adhocracy.

Figure 1: Competing Values Framework (CVF)

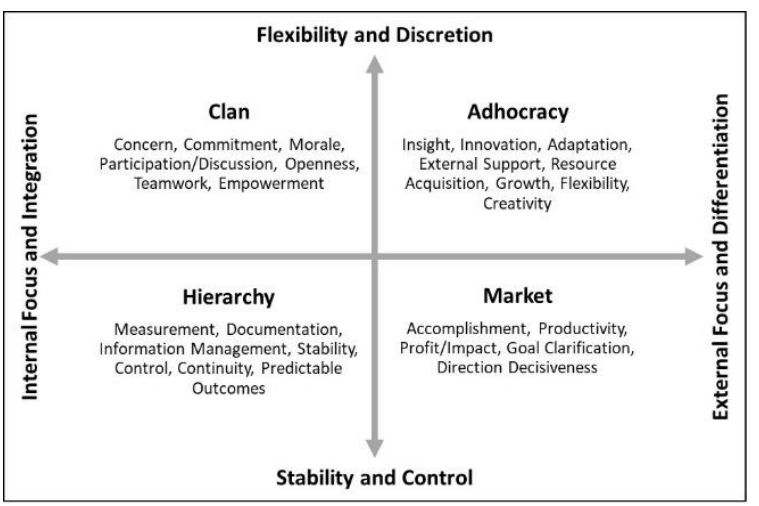

(Source: Cameron \& Quinn, 2006, p. 35)

\subsection{The Relationships between Organizational Culture Types and Modes of Whistleblowing}

Organizations with a typical hierarchical culture are well known by having features of a formalized and structured organizational setting. The most critical elements that are valued as a criterion for success include; strong lines of authority to make decisions, establishment of standardized rules and procedures, and methods of control and accountability. Some of the peculiar characteristics include; order, rules and regulations, uniformity and efficiency. Achieving a stable, predictable and efficient organization is the long-term concerns (Cameron \& Quinn, 2006). Organizations with hierarchical culture are often structured with a bureaucracy. The bureaucracy tends to have an inherent bias that strives to maintain status quo. One possible reason for this could be the characteristics of the power that exists in bureaucratic organizations. The power is used to regulate the flow of information and alterations to the group might provide information that disappoints those in power (Kowtha, Landau, \& Beng, 2001). Organizations that have very high vertical structures tend to impede internal whistleblowing. Employees in such a culture tend to show higher levels of discomfort in utilizing internal reporting methods (Park et al., 2008). Arguments and conflicts are not tolerated in hierarchical companies since they are perceived as irrational, violations of smoothly functioning procedure and disruption to efficiency (Trompenaars \& Turner, 1998). Elders, managers, superiors and authorities are highly valued in societies that are characterized by a high power distance. Organizations in high power distance countries tend to be dominated with hierarchical organizations (Hofstede, 1991). And since one of the theoretical philosophy of hierarchy is based on the principle of administrative authority to make decisions, organizations tend to show reluctance to blow the whistle on organizational wrongdoing (Smith, 2013). Thus, we hypothesized that:

H1: Hierarchy culture positively contributes to employees' intention towards external, anonymous, and formal whistleblowing.

H1a: Hierarchy culture positively contributes to employees` intention towards external whistleblowing.

H1b: Hierarchy culture positively contributes to employees ' intention towards anonymous whistleblowing.

H1c: Hierarchy culture positively contributes to employees` intention towards formal whistleblowing.

On the other hand, organizations characterized by a clan culture share their values and goals among all the organizational members. There is strong cohesion between employees and participation tends to be high. There is a sense of "we-ness" among employees and they resemble extended families. Some of the basic assumptions in these cultures include; developing employees, establishing effective teamwork and treating customers as partners. In addition, the organization continuously strives to establish a human work atmosphere (Cameron \& Quinn, 2006). Employees in a clan culture feel as if they are a family member towards each other and their organization. They like the connection they have with each other and the organization. Criticizing publicly is very rare and negative feedbacks are communicated indirectly. Employees exert 
maximum effort to avoid loss of face. The organization seems cohesive and pleasant with employees valuing a family and friendly feel within the organization where everyone looks out for each other (Trompenaars \& Turner, 1998). Employees might avoid external whistleblowing as it creates various fears and a feeling of discomfort. They may be regarded as accusers, lose trust and respect from teammates, and damage the bond with their organization (Karaca, 2013). Organizations characterized with a clan type of culture lack procedural norms and formalization. Employees tend to raise their concern on organizational wrongdoings through informal approaches and in a modest way (Kowtha et al., 2001). The intimacy, loyalty, easily approachable superiors, and family like feelings among the organizational members is likely to reduce the need to blow the whistle anonymously. Hence, we hypothesized that:

H2: Clan culture positively contributes to employees`intention towards internal, identified, and informal whistleblowing.

H2a: Clan culture positively contributes to employees` intention towards internal whistleblowing.

$\mathrm{H} 2 \mathrm{~b}$ : Clan culture positively contributes to employees` intention towards identified whistleblowing.

H2c: Clan culture positively contributes to employees 'intention towards informal whistleblowing.

The third type of organizational culture identified by the CVF is market culture. This culture focuses on the external environment and on developing the transactions found between the organization and several other external constituencies such as; clients, suppliers, traders, regulators/officials and the likes. The main emphasis is to carry out transactions with external bodies, gain competitive advantage, and maximizing; profit, outcomes, power in market, and secure clients. Competitiveness, productivity, strong determination and aggressive strategy to boosts production and profit are fundamental values. Major duty of management is to motivate the company in the direction of productivity and outcome. Similar to hierarchy culture, market culture also focuses on stability, order, and control. On the other hand, adhocracy culture emphasizes on possessing a work environment characterized by creativity and dynamism. Employees are expected to think or act freely and to develop/use their entrepreneurial skills. This culture aims to nurture adaptability, flexibility and creativity. Adhocracies are commonly considered to be the same with temporary. They are regarded as tents set up for temporary purpose instead of a permanent workstation. Power is not centralized and authority is not based on relations which is true for other types of cultures (e.g. hierarchy and market). This culture gives greater focus to individuality, empowers employees to take risk and imagine the future (Cameron \& Quinn, 2006). Concerning market and adhocracy culture types, there are no strong evidences in the extant literature that show the impact of these two types of cultures on whistleblowing intentions of employees. Therefore, a research question was asked in this study:

Q.1: Do the remaining types of organizational culture types (adhocracy and market) contribute to employees' intentions towards various types of whistleblowing?

\section{Figure 2: Theoretical Model}

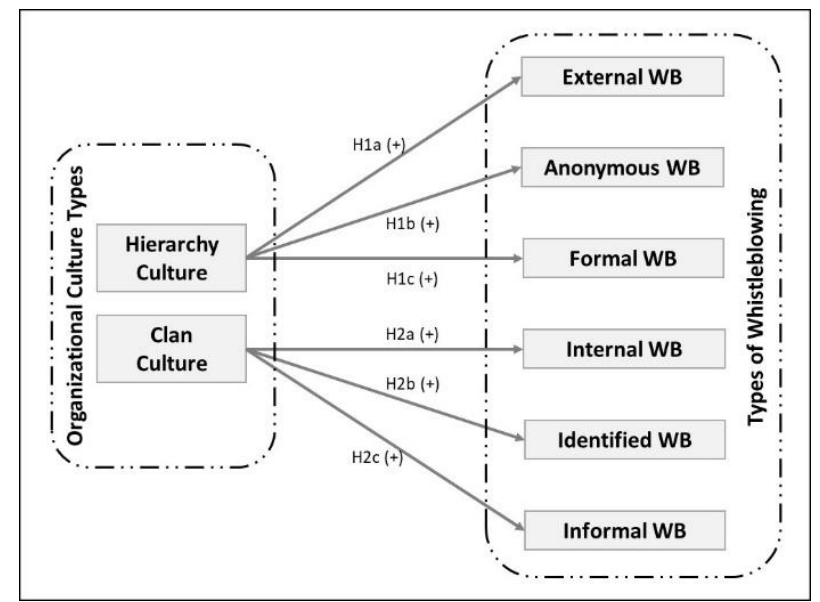

Theoretical model of the study can be seen in Figure 2. Since the purpose of this research is to investigate whistleblowing in non-western cultures, the theoretical model was tested in Ethiopia and Turkey. In addition to the proposed model, the current study also aims to examine the following research questions:

Q.2: Do employees in Ethiopia and Turkey differ in terms of their preference for a particular type(s) of whistleblowing? 


\section{METHODOLOGY}

\subsection{Participants}

A total of 528 voluntary employees from private and public organizations in Turkey (254) and Ethiopia (274) formed the sample for this study. Nearly 600 surveys were given to employees who were on duty from Jan-Mar, 2016 in Ethiopia and from April-June, 2016 in Turkey. All the participants were selected from Istanbul for Turkey and Addis Ababa for Ethiopia. The sample consisted of employees from a total of 13 private and 7 public organizations for Turkey and from 9 public and 11 private organizations for Ethiopia. The questionnaires were distributed using a hard copy and online system and the average completion time was 18 minutes. A response rate of $84 \%$ (Turkey) and $80 \%$ (Ethiopia) were obtained.

\subsection{Instruments}

Organizational culture was measured using the twenty four-item organizational culture assessment instrument (OCAI) developed by Cameron and Quinn (2006). The original OCAl in English was used with Ethiopian participants and the Turkish version translated by Öcal and Ağca (2010) was used for Turkish participants. Sample items include; "The glue that holds the organization together is loyalty and mutual trust. Commitment to this organization runs high," and "The organization is a very controlled and structured place. Formal procedures generally govern what people do". Whistleblowing was assed using a 14 item intentions towards types of whistleblowing (ITTW) scale developed by Park et al. (2008). Participants were presented with the following vignette: "Assume that the sales department of your company has committed the crime of tax evasion by manipulating its account books and receipts. An employee who has been working for the past 5 years discovers the wrongdoing one day by chance." Participants were then presented with the following question: "If he/she were to report the wrongdoing in any of the following ways, what would you think of his action?" The original English version of the scale is used for Ethiopian participants while the translated Turkish version (developed by a group of experts using back and forth translation system) was used for Turkish Participants. Sample items include; "He/she provides information to the prosecution/police", "He/she reports it to his supervisor", and "He/she reports while not revealing his identity". A 5-point interval scale ( 1 = strongly disagree, 5 = strongly agree) was used for both OCAI and ITTW scales.

\section{RESULTS}

\subsection{Validity and Reliability of Scales}

Initially, validity and reliability tests of the scales were conducted. ITTW were measured with six dimensions - representing six different types of whistleblowing - each with two or three indicators. These items were prepared to measure externalinternal, anonymous-identified, formal-informal whistleblowing types which are the two extremes of the three continuums and they are not used as a composite whistleblowing score. In this case, conducting a factor analysis to all items together is not meaningful, and for two-three item indicators conducting separate factor analyses become pointless as well. Therefore, only Cronbach's alpha reliability analyses were conducted and results are given in the Table 1 comparatively for Ethiopian and Turkish data.

Table 1: Reliability Analysis for Types of Whistleblowing Scales

\begin{tabular}{lccc}
\hline & & \multicolumn{2}{c}{ Reliability } \\
Types of whistleblowing & Item number & Ethiopia & Turkey \\
\hline External & 3 & .89 & .75 \\
Internal & 3 & .88 & .82 \\
Anonymous & 2 & .91 & .74 \\
Identified & 2 & .81 & .81 \\
Formal & 2 & .82 & .68 \\
Informal & 2 & .87 & .80 \\
\hline
\end{tabular}

As can be seen from the Table 1 above, the coefficients of Cronbach's $\alpha$ for all the scales used in the two countries suggest that the scales are reliable. The reliability scores for all the scales measuring the different types of whistleblowing were well above the acceptable level with a single exception for formal whistleblowing scale used with Turkish participants $(\alpha=.68)$.

The OCAl has a total of 24 question items representing four factors. There are 6 items under each of the four factors. These four factors represent a typical organizational culture type and are named as clan culture (CC), hierarchy culture (HC), market culture (MC) and adhocracy culture (AC). To assess the reliability and validity of the OCAl, confirmatory factor analysis (CFA) was conducted separately for data obtained from Ethiopian and Turkish participants (See Table 2). Due to low item loading (less than .50), one item of adhocracy culture in Ethiopian sample, and one item of clan culture in Turkish sample were eliminated. The results indicated acceptable fit for both Ethiopia $(\chi 2(224, N=278)=438.96, p=0.00, C F I=.93$, 
$\mathrm{TLI}=.92, \mathrm{RMSEA}=.06, \mathrm{SRMR}=.06)$ and Turkey $(\chi 2(224, \mathrm{~N}=254)=414.61, \mathrm{p}=0.00, \mathrm{CFI}=.92, \mathrm{TLI}=.91, \mathrm{RMSEA}=.05, \mathrm{SRMR}=.05)$. We analyzed further to check for convergent validity and discriminant validity. All factor loadings for both samples were relatively high and significant, providing evidence for convergent validity (Bagozzi \& Yi, 1988). Also, the construct reliability (CR) values of organizational culture factors in both samples were all above .70 acceptable level indicating high internal consistency of the dimensions (Hair, Black, Babin, Anderson, \& Tatham, 2006). Average variance extracted (AVE) values, which reflect the overall amount of variance accounted for by the latent constructs, were all above .50 threshold (Fornell \& Larcker, 1981).

Table 2: Confirmatory Analysis of Organizational Culture Scale

\begin{tabular}{|c|c|c|c|c|c|c|}
\hline \multirow[b]{2}{*}{ Constructs } & \multicolumn{3}{|c|}{ Ethiopia } & \multicolumn{3}{|c|}{ Turkey } \\
\hline & Item number & CR & AVE & Item number & CR & AVE \\
\hline Adhocracy & 5 & .78 & .42 & 6 & .80 & .40 \\
\hline Clan & 6 & .88 & .55 & 5 & .78 & .42 \\
\hline Hierarchy & 6 & .88 & .55 & 6 & .86 & .52 \\
\hline Market & 6 & .89 & .57 & 6 & .90 & .60 \\
\hline
\end{tabular}

Ethiopia sample $\chi^{2}(224, N=278)=438.96, p=.00, \mathrm{CFI}=.93, \mathrm{TLI}=.92, \mathrm{RMSEA}=.06, \mathrm{SRMR}=.06$

Turkey sample $\chi^{2}(224, N=254)=414.61, p=.00, \mathrm{CFI}=.92, \mathrm{TLI}=.91, \mathrm{RMSEA}=.05, \mathrm{SRMR}=.05$

$\mathrm{CR}=$ Construct Reliability; $\mathrm{AVE}=$ Average variance extracted

\subsection{Describing Research Variables in Ethiopian and Turkish Settings}

Descriptive statistics of variables were calculated to profile our samples from both countries. Then, statistical tests were applied to find out if there were any differences in these variables in the two settings.

Table 3: Descriptive Statistics and Friedman two-way ANOVA Test Results for Whistleblowing Types

\begin{tabular}{lcccccc}
\hline & \multicolumn{3}{c}{ Ethiopia (N=278) } & & \multicolumn{3}{c}{ Turkey (N=254) } \\
\hline Variables & $\mathbf{M}$ & SD & M rank & M & SD & M rank \\
\hline External & 3.13 & 1.11 & 3.30 & 2.77 & 1.03 & 2.89 \\
Internal & 3.31 & 1.09 & 3.65 & $\mathbf{3 . 8 7}$ & 0.93 & $\mathbf{4 . 4 5}$ \\
Anonymous & 3.39 & 1.07 & 3.67 & 3.27 & 1.04 & 3.49 \\
Identified & 3.10 & 1.09 & 3.32 & 2.75 & 1.09 & 2.88 \\
Formal & $\mathbf{3 . 6 8}$ & 1.01 & $\mathbf{4 . 1 1}$ & $\mathbf{3 . 9 0}$ & 0.94 & $\mathbf{4 . 5 9}$ \\
Informal & $\mathbf{2 . 8 4}$ & 1.15 & $\mathbf{2 . 9 6}$ & $\mathbf{2 . 6 1}$ & 1.05 & $\mathbf{2 . 6 9}$ \\
\hline
\end{tabular}

Friedman Test Ethiopia sample $\chi^{2}(5, N=278)=66.47, p=.00$

Friedman Test Turkey sample $\chi^{2}(5, N=254)=284.90, p=.00$

As can be seen from Table 3 above, Ethiopian sample indicated their intentions a little above average (score $=3$ ) for all types except informal whistle blowing, which is preferred less than average. However, Turkish sample indicated only three types above average (internal, anonymous, and formal) and the other three less than average. To find out if there is actually a difference in the preferred whistleblowing behavior, Friedman one-way ANOVA tests were conducted to both samples. The results revealed that the degree of preference between six types of whistleblowing intentions were statistically different in both Ethiopia and Turkey samples $\left(\chi^{2}(5, N=278)=66.47, p=.00 ; x^{2}(5, N=254)=284.90, p=.00\right.$ respectively).

The most preferred whistleblowing behavior in Ethiopia was 'formal' and the least preferred was 'informal'. Employees' preference for 'formal' whistleblowing scores $(M=3.68)$ was significantly higher than all the remaining types of whistleblowing with the highest mean rank (4.11). 'Informal' whistleblowing ( $M=2.83)$ tends to be the least preferred type of whistleblowing with the lowest mean rank (2.96). In Turkish sample, the two most preferred whistleblowing behaviors were 'formal' $(M=3.90)$ and 'internal' $(M=3.87)$ and the least preferred was 'informal' $(M=2.60)$ with a mean rank of 4.59, 4.45 and 2.69 respectively. So we can say, even though means indicated differences in the intention to show different whistleblowing intentions between Ethiopia and Turkey, the most and least preferred methods were same. Subsequently, to find out statistically, if ITTW show difference in terms of country of origin, a series of independent t-tests were conducted. Results can be found in Table 4 below. It was found out that with the exception of anonymous whistleblowing, Turkish and Ethiopian employees showed statistically significant difference in terms of the five types of whistleblowing. 
Table 4: Independent Sample T-test Results of Whistleblowing Types in terms of Cultures

\begin{tabular}{|c|c|c|c|c|c|c|c|}
\hline Variables & Samples & $\mathbf{N}$ & M & SD & $\mathbf{t}$ & df & p \\
\hline \multirow{2}{*}{ External } & Ethiopia & 278 & 3.12 & 2.76 & \multirow{2}{*}{-3.87} & \multirow{2}{*}{530} & \multirow{2}{*}{.00} \\
\hline & Turkey & 254 & 2.76 & 1.02 & & & \\
\hline \multirow{2}{*}{ Internal } & Ethiopia & 278 & 3.31 & 1.09 & \multirow{2}{*}{6.36} & \multirow{2}{*}{527} & \multirow{2}{*}{.00} \\
\hline & Turkey & 254 & 3.87 & .92 & & & \\
\hline \multirow{2}{*}{ Identified } & Ethiopia & 278 & 3.10 & 1.08 & \multirow{2}{*}{-3.73} & \multirow{2}{*}{530} & \multirow{2}{*}{.00} \\
\hline & Turkey & 254 & 2.75 & 1.08 & & & \\
\hline \multirow{2}{*}{ Formal } & Ethiopia & 278 & 3.68 & 1.00 & \multirow{2}{*}{2.57} & \multirow{2}{*}{530} & \multirow{2}{*}{.01} \\
\hline & Turkey & 254 & 3.90 & .93 & & & \\
\hline \multirow{2}{*}{ Informal } & Ethiopia & 278 & 2.83 & 1.14 & \multirow{2}{*}{-2.44} & \multirow{2}{*}{529} & \multirow{2}{*}{.02} \\
\hline & Turkey & 254 & 2.60 & 1.05 & & & \\
\hline
\end{tabular}

Turkish participants preference for internal $(M=3.87)$ and formal $(M=3.90)$ whistleblowing were significantly higher than Ethiopian participants intention for internal $(M=3.31)$ and formal (3.68) whistleblowing. On the other hand, Ethiopian participants showed higher preference for external $(M=3.12)$, identified $(M=3.10)$ and informal $(M=2.83)$ whistleblowing than Turkish participants who rated relatively less on external $(M=2.76)$, identified $(M=2.75)$ and informal (2.60) whistleblowing.

\subsection{Model Testing}

A series of multiple regression analyses were conducted to test the hypothesized model. Each of the four culture types significantly contributed to the various modes of employees' whistleblowing intentions. As shown in Table 5 below, hierarchy culture positively contributed to intentions towards external whistleblowing for Ethiopia $(\beta=.17, t=2.53, p<.05)$ and Turkey $(\beta=.14, t=2.32, p<.05)$. The contribution of market culture is also positive for Turkish sample $(B=.19, t=3.11$, $p<.01)$. However, clan culture for Turkish sample $(\beta=-.18, t=-2.93, p<.01)$ and adhocracy culture for Ethiopian sample $(\beta=-$ $.23, \mathrm{t}=-3.73, \mathrm{p}<.01)$ negatively contributed to external whistleblowing intentions. However, with regards to anonymous whistleblowing, with the exception of hierarchy culture for Ethiopian sample that showed positive contribution ( $\beta=.31$, $t=4.0, p<.001)$, none of the remaining cultural types showed significant contribution.

Table 5: Regression Analyses Result for External, Anonymous, and Formal Whistleblowing

\begin{tabular}{|c|c|c|c|c|c|c|c|c|c|c|c|c|}
\hline & \multicolumn{4}{|c|}{ External Whistleblowing } & \multicolumn{4}{|c|}{ Anonymous Whistleblowing } & \multicolumn{4}{|c|}{ Formal Whistleblowing } \\
\hline & \multicolumn{2}{|c|}{ Ethiopia } & \multicolumn{2}{|c|}{ Turkey } & \multicolumn{2}{|c|}{ Ethiopia } & \multicolumn{2}{|c|}{ Turkey } & \multicolumn{2}{|c|}{ Ethiopia } & \multicolumn{2}{|c|}{ Turkey } \\
\hline Independent variables & $\beta$ & $\mathbf{t}$ & $\beta$ & $\mathbf{t}$ & $\beta$ & $\mathbf{t}$ & $\beta$ & $\mathbf{t}$ & $\beta$ & $\mathbf{t}$ & $\beta$ & $\mathbf{t}$ \\
\hline Clan & .03 & .40 & -.18 & $-2.93 * *$ & .06 & .78 & -.08 & -1.36 & -.01 & -.14 & -.27 & $-4.54^{* * *}$ \\
\hline Hierarchy & .14 & $2.53 * *$ & .14 & $2.32 *$ & .31 & $.40 * * *$ & -.01 & -.21 & .23 & $2.76^{* *}$ & .17 & $2.80 * *$ \\
\hline Adhocracy & -.23 & $-3.73 * *$ & -.10 & -1.62 & -.02 & -.36 & -.08 & -1.24 & -.25 & $-3.70 * * *$ & -.07 & -1.23 \\
\hline Market & .13 & 1.55 & .19 & $3.11^{* *}$ & .15 & $2.70^{* *}$ & -.09 & -1.44 & .01 & .16 & -.03 & -.63 \\
\hline $\mathbf{R}$ & & & & 31 & & 1 & & 6 & & & & 3 \\
\hline $\mathbf{F}$ & & & & $7^{* *}$ & & $0 * * *$ & & & & $* * *$ & & $16 * * *$ \\
\hline
\end{tabular}

The contribution of hierarchy culture on formal whistleblowing was also positive for both Ethiopian $(\beta=.23, t=2.76, p<.01)$ and Turkish $(\beta=.17, t=2.80, p<.01)$ samples. In contrast, clan culture for Turkish sample $(\beta=-.27, t=-4.54, p<.001)$ and adhocracy culture for Ethiopian sample $(\beta=-.25, t=-3.70, p<.001)$ showed negative contribution to formal whistleblowing intentions. The overall result obtained from the regression analyses showed that, with the exception of anonymous whistleblowing in Turkish sample, hierarchical culture significantly and positively contributed to external, anonymous, and formal whistleblowing intentions of employees. However, the explanatory power of hierarchy culture for the observed variance in these three types of whistleblowing was moderately low in both samples. Thus, Hypothesis 1a and Hypothesis $1 \mathrm{c}$ are supported while Hypothesis $1 \mathrm{~b}$ is partially supported.

Table 6: Regression Analyses Result for Internal, Identified, and Informal Whistleblowing

\begin{tabular}{|c|c|c|c|c|c|c|c|c|c|c|c|c|}
\hline \multirow[b]{3}{*}{ Independent variables } & \multicolumn{4}{|c|}{ Internal Whistleblowing } & \multicolumn{4}{|c|}{ Identified Whistleblowing } & \multicolumn{4}{|c|}{ Informal Whistleblowing } \\
\hline & \multicolumn{2}{|c|}{ Ethiopia } & \multicolumn{2}{|c|}{ Turkey } & \multicolumn{2}{|c|}{ Ethiopia } & \multicolumn{2}{|c|}{ Turkey } & \multicolumn{2}{|c|}{ Ethiopia } & \multicolumn{2}{|c|}{ Turkey } \\
\hline & $\beta$ & $\mathbf{t}$ & $\beta$ & $t$ & $\beta$ & $t$ & $\beta$ & $\mathbf{t}$ & $\beta$ & $\mathbf{t}$ & $\boldsymbol{\beta}$ & $\mathbf{t}$ \\
\hline Clan & .30 & $5.05 * * *$ & .14 & $2.25^{*}$ & .19 & 1.33 & .00 & .01 & .35 & $5.42 * * *$ & .00 & .07 \\
\hline Hierarchy & -.16 & $-1.99 *$ & -.15 & $-2.45^{*}$ & -.15 & -1.76 & -.03 & -.53 & -.08 & -1.00 & -.05 & -.84 \\
\hline Adhocracy & -.02 & $-3.73 * *$ & .04 & .69 & -.06 & -.94 & .05 & .74 & -.17 & -1.38 & -.08 & -1.23 \\
\hline Market & -.04 & 1.55 & .04 & .65 & -.07 & -1.15 & .05 & .72 & -.08 & -1.35 & -.13 & $-2.10^{*}$ \\
\hline $\mathbf{R}$ & \multicolumn{2}{|c|}{.33} & \multicolumn{2}{|c|}{.21} & \multicolumn{2}{|c|}{.15} & \multicolumn{2}{|c|}{.07} & \multicolumn{2}{|c|}{.32} & \multicolumn{2}{|c|}{.17} \\
\hline $\mathbf{F}$ & \multicolumn{2}{|c|}{$8.40 * * *$} & \multicolumn{2}{|c|}{$2.88^{*}$} & \multicolumn{2}{|c|}{1.62} & \multicolumn{2}{|c|}{.33} & \multicolumn{2}{|c|}{$7.62 * * *$} & \multicolumn{2}{|c|}{1.80} \\
\hline
\end{tabular}


With regards to internal whistleblowing, Table 6 above depicts that clan culture positively contributed to internal whistleblowing for both Ethiopian $(\beta=.30, t=5.05, p<.001)$ and Turkish $(\beta=.14, t=2.25, p<.05)$ samples. On the other hand, hierarchy culture negatively contributed to internal whistleblowing both in Turkey $(\beta=-.15, t=-2.45, p<.05)$ and Ethiopia $(\beta=-$ $.16, \mathrm{t}=-1.99, \mathrm{p}<.05)$. Also, for Ethiopian sample, adhocracy culture showed negative contribution to internal whistleblowing. The results also revealed two significant results with regards to informal whistleblowing. For Ethiopian sample, clan culture showed positive contribution $(\beta=.35, t=5.42, p<.001)$ while market culture for Turkish sample showed negative contribution $(\beta=-.13, t=-2.10, p<.05)$ to informal whistleblowing. However, all the four organizational culture types in both samples did not show significant contribution to identified whistleblowing. Thus, Hypothesis $2 \mathrm{a}$ is supported, Hypothesis $2 \mathrm{c}$ is partially supported, and Hypothesis $2 b$ is not supported.

\section{CONCLUSION AND DISCUSSION}

The main purpose of the current study was to examine the contribution of organizational culture types on employees' intentions towards various mode(s) of whistleblowing. The study also aimed to find out whether employees in Ethiopia and Turkey differ in terms of their preference for a particular type(s) of whistleblowing. The results of the analysis are discussed in the following section.

In this study, we proposed that hierarchy type of organizational culture positively contributes to employees 'intention towards external, anonymous and formal whistleblowing. The results supported the hypothesis, with exception of anonymous whistleblowing in Turkish sample. Even though we did not come across previous empirical studies that particularly tested the association between hierarchy culture and whistleblowing types, there are some strong evidences in related research and theoretical explanations that demonstrate cultural dimensions and organizational structures relate with types of whistleblowing. For example, King (1999) argued that in organizations with a typical hierarchical or bureaucratic character, reporting organizational misconduct tends to be less open and frequent. A study conducted by Chang and Lu (2007) also found out that in Taiwanese organizations - characterized by a strong sense of administrative ethics, conformity and admiration to superiors - when the opinions of employees differs from that of superiors, employees are expected to accept the views and directives of the superiors without challenging them in an open way. Discussing ethical issues openly was found to have a positive association with confrontation and reporting internally. But it has a negative association with blowing the whistle externally (Kaptein, 2011). An experiment carried out to identify the role of anonymous whistleblowing also revealed that employees' intention to whistleblow on organizational misconduct increased when their identities were kept secure (Mecca et al., 2014). The costs associated with blowing the whistle anonymously is perceived to be lower than that of reporting in identified way (Kaplan \& Schultz, 2007).

We also proposed that clan culture positively contributes to employees' intention towards internal, identified and informal whistleblowing. Except for identified type of whistleblowing, the results generally supported the proposed hypothesis. This finding is supported by previous studies and theoretical propositions. For example, Miethe and Rothschild (1994) argued that in organizations which are relatively smaller, less bureaucratic, less formalized, and that are highly participative, employees are likely to have relatively higher rates of internal rather than external whistleblowing. Clan cultures have relatively flat hierarchies and the major controlling mechanisms of written rules and regulations are minimized or lacking. The unwritten norms and regulations tend to create higher levels of influence on members revealing organizational misconduct in such a way that employees will be generally less likely to whistleblow the misconduct of team members (Miller \& Thomas, 2005). And if they decide to report a misconduct, they may more likely to report it internally and informally. In addition, the preference for internal whistleblowing in clan culture could be explained by the theory of planned behavior (TPB). According to TPB, intention to carry out a certain behavior (in this case type of whistleblowing) is influenced by underlying beliefs that one experiences. One of these beliefs is subjective norm which refers to the perceived social pressure one experiences either to perform or not to perform the behavior (Park \& Blenkinsopp, 2009). Thus, employees in clan culture are more likely to prefer a comfortable friendly relation with other colleagues in the workplace instead of initiating conflict by blowing a whistle on the misconduct of others to external agents.

Our study further revealed that market culture significantly and positively contributed to external and anonymous whistleblowing. One possible explanation for this could be that organizations with market culture are considered to function as a market themselves. Their orientation is towards external surroundings rather than internal matters (Cameron \& Quinn, 2006). The focus and connection with external environment in market cultures could be one possible factor that influences employees in such cultures to prefer external whistleblowing. Power gaps between levels is also very low because information tends to flow freely. Due to inequality of power and lower dependency, employees tend to make decisions based on their personal self-interest. In such cultures, legitimacy is bestowed by compromise and resolution, and not by decree (Kowtha et al., 2001). Thus, reporting organizational misconduct to external constituents could be easy and employees may likely engage in such intentions. In addition, information is very widely diffused and highly codified in market cultures. Employees in such cultures tend to have the chance to collect and interpret information they desire by themselves. Due to this, decisions are made autonomously and can be determined by self-interest. There are no identity- 
based associations and there are limited guidelines that govern employees to speak-up or voice their interest at a convenient time and place (Kowtha et al., 2001). Thus, employees working in organizations that are dominated with values of market culture could prefer external and anonymous whistleblowing due to these reasons.

Our study also found out that adhocracy culture had significant negative contribution to both external and formal whistleblowing. Adhocracy culture emphasizes creativity, innovation and fostering entrepreneurship. In this culture, power is decentralized and there is no authority relationships (Cameron \& Quinn, 2006). Thus, employees might not be afraid to raise their concern to those working in the same organization, hence minimizing the need to whistleblow externally. Also, the adhocracy culture corresponds to and tends to possess similar characteristics to that of what Trompenaars and Turner (1998) called the incubator culture. In such cultures, employees tend to have very close relationships, shared interests and superordinate goals. There is high dependence on face-to-face interaction and intimacy. Rhee and Moon (2009) also found out that adhocracy culture is positively related with information adequacy. Adhocracy cultures are more likely to offer sufficient information to their staffs about individual and organizational issues. In addition, adhocracy culture has a positive effect on information flow and interaction supportiveness. The authors argued that this type of culture tends to enhance a free flow of information and a positive communication atmosphere whereby employees listen to each other actively, manage clashes, and show sympathy towards each other. Thus, as this study found out, employees in this type of culture may less likely incline to prefer external and formal whistleblowing to reveal organizational misconduct.

Concerning preferred mode of whistleblowing in the two countries, overall, our study found out that employees' intentions towards types of whistleblowing in the two nations is very similar. In both samples, the most preferred is formal whistleblowing while the least preferred is informal whistleblowing. The higher level of preference for formal whistleblowing in both countries might be due to the existence of higher degrees of uncertainty avoidance in the two nations. This finding tends to be in line with some of the previous studies. For example, Hofstede (1991), identified Turkey as a country with national culture that is dominated by higher index levels of uncertainty avoidance (85). Ethiopia also scored little above average on uncertainty avoidance index (52). In a typical organization dominated with strong uncertainty avoidance culture (like Turkey and Ethiopia), rules and procedures to govern the environment are more likely to prevail. In such organizations, little is left open to chance or interpretation and employees tend to stick to the already established formal system (Tavakoli, et al., 2003). Thus, the higher preference for formal and lower preference for informal whistleblowing in both nations could be attributed to the higher degrees of uncertainty avoidance. The second most preferred type of whistleblowing is internal for Turkey and anonymous for Ethiopia. On the remaining types of whistleblowing, the preferences are nearly the same indicating very close similarity. The preference for internal as the second most preferred type of whistleblowing among Turkish participants is similar with Park et al.'s (2008) cross-cultural study that compared Turkey, UK, and South Korea on preference towards six types of whistleblowing. The authors reported that, generally, there is a preference for internal, formal, and anonymous over other types of whistleblowing in Turkey. The overall result tends to indicate that in all the three pairs of whistleblowing types, the mean difference is relatively higher for Turkey compared to Ethiopia.

Based on the findings of the current study, we can conclude that the dominant values and beliefs embedded within the culture of an organization tend to determine the most likely expected and acceptable methods of whistleblowing in that particular organization. Even though organizational culture types in both countries significantly predicted the various types of whistleblowing almost in similar ways, the observed effect sizes were not very high. As the main implication of the current study, we would like to emphasize that whistleblowing policies at organizational level should consider their prevailing dominant cultural values while formulating guidelines on how their employees report organizational misconducts easily. Mecca et al., (2014) suggested that organizational policies must protect whistleblowers from possible reprisal and give the chance to report what they know without fear. In short, policy makers, leaders, and managers need to make sure that their employees have adequate access to the various whistleblowing channels, especially channels that are congruent with the dominant cultural values of their organization, and that potential whistleblowers in the organization need to perceive the established channels as acceptable, easy and appropriate to report unethical events they come across in their workplace.

Lastly, we would like to acknowledge that the results of the study should be appraised with some potential limitations. One potential limitation can be the scenario approach utilized to investigate participants' intention towards types of whistleblowing. The single scenario, which deals about one specific topic (tax evasion) was very specific. This could influence their preference towards a particular type of whistleblowing, may be that their response about their intentions towards a particular type of whistleblowing could relate with the specific type of organizational misconduct presented in the scenario. Also conditions in the real world contain more information related to an ethical event compared to the misconduct presented in the vignette used for the current study. Moreover, the generalizability of the findings are limited with the sizes of samples in both countries, further studies are required to verify the results of the current research. In 
general, however, the results appear to be enlightening and encouraging, and we hope that they will enhance the groundwork for additional similar studies in this area especially in a non-Western cultures.

\section{REFERENCES}

Alvesson, M. 2002, "Understanding organizational culture". London: SAGE Publications Ltd.

Bagozzi R.P. \& Yi, Y. 1988, “On the evaluation of structural equation models”. Journal of the Academy of Marketing Science, 16 (1), pp.7494.

Barnett, T. 1992, "A preliminary investigation of the relationship between selected organizational characteristics and external whistleblowing by employees". Journal of Business Ethics, 11(12), pp. 949-959.

Chang, K., \& Lu, L. 2007, "Characteristics of organizational culture, stressors and wellbeing: The case of Taiwanese organizations". Journal of Managerial Psychology, 22 (6), pp. 549-568. doi: 10.1108/02683940710778431

Cameron, K. S., \& Quinn, R. E. 2006, "Diagnosing and changing organizational culture: Based on the competing values framework". San Francisco, CA: Jossey-Bass.

Chung, J., Monroe, G., \& Thorne, L. 2004, "An examination of factors affecting external and internal whistle-blowing by auditors". Paper presented at research seminar, session 1, University of NSW School of Accounting, Australia. Retrieved from http://wwwdocs.fce.unsw.edu.au/accounting/news/ seminars2004_s1/paper03.pdf, (May 13, 2016).

Donkin, M., Smith, R., \& Brown, A. J. 2008, "How do officials report? Internal and external whistleblowing". In J. A. Brown (Eds.), Whistleblowing in the Australian public sector: Enhancing the theory and practice of internal witness management in public sector organizations (pp. 83-108). Canberra: ANUE Press.

Dworkin, T. M., \& Baucus, M. S. 1998, “Internal vs. external whistleblowers: A comparison of whistleblowing processes”. Journal of Business Ethics, 17, pp. 1281-1298.

Finn, D. W. 1995, "Ethical decision-making in organizations: A management employee-organization whistle-blowing model". Research on Accounting Ethics, 1, pp. 293-313.

Fornell, C., \& Larcker, F. D. 1981, "Evaluating structural equation models with unobservable variables and measurement error". Journal of Marketing Research, 18, pp. 39-50.

Hair, Jr. F. J., Black C. W., Babin J. B., Anderson E. R., \& Tatham, L. R. 2006, “Multivariate data analysis". Upper Saddle River, NJ: Prentice Hall Inc.

Hofstede, G. 1990, "Measuring organizational cultures: A qualitative and quantitative study across twenty cases". Administrative Science Quarterly, 35, pp. 286-316.

Hofstede, G. 1991, “Cultures and Organizations: Software of the Mind”. London, McGraw-Hill.

Johansson, E., \& Carey, P. 2015, “Detecting fraud: The role of the anonymous reporting channel”. Journal of Business Ethics, 139 (2), pp. 391-409. doi: 10.1007/s10551-015-2673-6

Kaplan, S. E., \& Schultz, J. J. 2007, "Intentions to report questionable acts: An examination of the influence of anonymous reporting channel, internal audit quality and setting". Journal of Business Ethics, pp. 71, 109-124.

Kaptein, M. 2011, "From inaction to external whistleblowing: The influence of the ethical culture of organizations on employee responses to observed wrongdoing". Journal of Business Ethics, 98, pp. 513-530. doi: 10.1007/s10551-010-0591-1

Karaca, H. 2013, "An exploratory study on the impact of organizational silence in hierarchical organizations: Turkish national police case". European Scientific Journal, vol. 9, Pp. 38-50.

King, G., III. 1999, “The implications of an organization's structure on whistleblowing”. Journal of Business Ethics, 20 (4), pp. 315-326.

Kowtha, R., Landau, J., \& Beng, C. H. 2001, "The culture of voice: Exploring the relationship between employee voice and organizational culture". In Academy of Management Conference, Washington, DC. Retrieved from http://researchgate.net/profile/Rao kowtha/publicatio n/265524987, (May 3, 2015).

Lewis, D. 2002, "Five years on-The organizational culture saga revisited". Leadership and Organization Development Journal, 23, pp. 280287.

Loyens, K. 2013, "Towards a custom-made whistleblowing policy. Using grid-group cultural theory to match policy measures to different styles of peer reporting". Journal of Business Ethics, 114, pp. 239-249. doi: 10.1007/s10551-012-1344-0

MacIntosh, E. W., \& Doherty, A. 2010, "The influence of organizational culture on job satisfaction and intention to leave". Sport Management Review, 13, pp. 106-117. 
MacNab, B., Brislin, R., Worthley, R., Galperin, B., Jenner, S., Lituchi, T., MacLean, J., Aguilera, M. G., Ravlin, E., Tiessen, H. J., Bess, D., \& Turcotte, M. 2007, "Culture and ethics management: External whistle-blowing and internal reporting within a NAFTA member context". International Journal of Cross-Cultural Management, 7, pp. 5-28.

Martin, J., \& Siehl, C. 1983, “Organizational culture and counterculture: An uneasy symbiosis”. Organizational Dynamics, 12 (2), pp.52-86.

Martin, P. 2010, "The status of whistleblowing in South Africa-Taking stock". Retrieved fromhttp://www.opendemocracy.org.za/wpcontent/uploads/2010/10/ODAC_Whistleblowing_Report_web.pdf, (October 10, 2013).

Mecca, J. T., Giorgini, V., Medeiros, K., Gibson, C., Devenport, L., Connelly, S., \& Mumford, M. 2014, "Perspectives on whistleblowing: Faculty member viewpoints and suggestions for organizational change". Accountability in Research, 21, pp. 159-175. doi: $10.1080 / 08989621.2014 .847735$

Mesmer-Magnusm, J. R., \& Viswesvaran, C. 2005, "Whistleblowing in organizations: An examination of correlates of whistleblowing intentions, actions, and retaliation". Journal of Business Ethics, 62, pp. 277-297. doi: 10.1007/s10551-005-0849-1

Miceli, M. P., \& Near, J. P. 1992, "Blowing the whistle: The organizational and legal implications for companies and employees". New York: Lexington.

Miceli, M. P., \&, Near, J. P. 1994, "Relationships among value congruence, perceived victimization and retaliation against whistle-blowers". Journal of Management, 20 (4), pp. 773-794.

Miceli, M. P \& Near, J.P. 1995, “Effective whistle-blowing”. The Academy of Management Review, 20 (3), pp. 679-708.

Miceli, M. P., Near, J. P \& Dworkin, T. M. 2008, “Whistle-blowing in organizations”. New York, NY: Routledge.

Miethe, T. D., \& Rothschild, J. 1994, "Whistleblowing and the control of organizational misconduct". Sociological Inquiry, 64 (3), pp. $322-$ 347.

Miller, D. L., \& Thomas, S. 2005, "The impact of relative position and relational closeness on the reporting of unethical acts". Journal of Business Ethics, 61, pp. 315-328. doi: 1007/s10551-005-8771-0

Nayır, D. Z., Rehg, M. T., \& Asa, Y. 2016, "Influence of ethical position on whistleblowing behavior: Do preferred channels in private and public sectors differ?" Journal of Business Ethics, pp. 1-21. doi: 10.1007/s10551-016-3035-8

Near, J. P., \& Miceli, M. P. 1985, “Organizational dissidence: The case of whistle-blowing”. Journal of Business Ethics, 4, pp. 1-16.

Near, J. P., \& Miceli, M. P. 1986, “Retaliation against whistle-blowers: Predictors and effects”. Journal of Applied Psychology, 71(1), pp. 137145.

Öcal, H., \& Ağca, V. 2010, "The effects of different industry structures depending on the speed of technological change on the organizational culture and business performance". Ege Academic Review, 10 (1), pp. 157-182.

Park, H., Blenkinsopp, J., Oktem, M. K., \& Omurgonulsen, U. 2008, "Cultural orientation and attitudes toward different forms of whistleblowing: A comparison of South Korea, Turkey, and the U.K". Journal of Business Ethics, 82, pp. 929-939.

Park, H., \& Blenkinsopp, J. 2009, "Whistle-blowing as planned behavior - A survey of South Korean police officers". Journal of Business Ethics, 85 (4), pp. 545-556.

Park, H., Blenkinsopp, J., \& Park, M. 2014, “The Influence of an observer's value orientation and personality type on attitudes toward whistleblowing". Journal of Business Ethics, 120, pp. 121-129. doi: 10.1007/s10551-013-1908-7

Pierre, B. 2012, "Whistleblowing". In Cote, L. \& Savard, J. F. (Eds.). Encyclopedic Dictionary of Public Administration. Retrieved from http://www.dictionnaire.en ap.ca, (December 10, 2015).

Philmore, A., Mohammad, H., \& Richard, P. 2013, "Towards a conceptual model of whistle-blowing intentions among external auditors". The British Account Review, 45, pp. 10-23.

Ponemon, L. 1994, "Comment: Whistle-blowing as an internal control mechanism: Individual and organizational considerations". Journal of Practice and Theory, 13(2), pp. 118-130.

Rhee, Y., \& Moon, B. 2009, “Organizational culture and strategic communication practice: Testing the competing values model (CVM) and employee communication strategies (ECS) model in Korea". International Journal of Strategic Communication, 3 (1), pp. 52-67. doi: $10.1080 / 15531180802608386$

Robinson, S. N., Robertson, J. C., \& Curtis, M. B. 2012, “The effects of contextual and wrongdoing attributes on organizational employees' whistleblowing intentions following fraud". Journal of Business Ethics, 106, pp. 213-227.

Schein, E. H. 1991, "The role of the founder in the creation of organizational culture". In P. J. Frost, L. F. Moore, M. R. Louis, C. C. Lundberg, \& J. Martin (Eds.), Reframing organizational culture (pp. 14-25). Beverly Hills, CA: Sage.

Smircich, L. 1983, “Concepts of culture and organizational analysis". Administrative Science Quarterly, 28 (3), pp. 339. 
Smith, R. 2013, "Whistleblowing and hierarchical bureaucracy: Re-thinking the relationship". E-Journal of International and Comparative Labor Studies, 2 (3), pp. 1-24.

Somers, M. J., \& Casal, J. C. 1994, "Organizational commitment and whistle-blowing: A test of the reformer and the organization man hypotheses". Group and Organization Management, 19 (3), pp. 270-83.

Tavakoli, J. P., Keenan, B \& Karanovic, C. 2003, "Culture and whistleblowing: An empirical study of Croatian and United States managers utilizing Hofstede's cultural dimensions". Journal of Business Ethics, 43, pp. 49-64.

Trompenaars, F., \& Turner, H. C. 1998, "Riding the Waves of Culture: Understanding Cultural Diversity in Global Business". New York: McGraw-Hill.

Vandekerckhove, W. 2006, “Whistleblowing and Organizational Social Responsibility: A Global Assessment”. Aldershot: Ashgate.

Vandekerckhove, W. 2010, "Whistleblowing. Perennial issues and ethical risks". In G.Aras \& D. Crowther (Eds.), Handbook of corporate governance and social responsibility. Farnham: Gower. 